\title{
The diagnosis and management of hypothalamic hamartomas in children
}

\author{
Baocheng Wang and Jie Ma*
}

\begin{abstract}
Hypothalamic hamartoma $(\mathrm{HH})$ is a rare developmental malformation often characterized by gelastic seizures. Recent advances in treating $\mathrm{HH}$ have led to dramatic improvements. However, clinical protocol of $\mathrm{HH}$ is poorly understood. Since 2002, department Pediatric Neurosurgery of Xinhua Hospital has maintained a multidisciplinary clinical program to evaluate and treat children with $\mathrm{HH}$. This program has provided the opportunity to investigate the management of $\mathrm{HH}$. In this review, we summarize the clinical progress and propose a clear management principle for different $\mathrm{HH}$ patients.
\end{abstract}

Keywords: Hypothalamic hamartoma, Gelastic seizures, Central precocious puberty, Electroencephalogram, Treatment

\section{Background}

Hypothalamic hamartomas $(\mathrm{HH})$ are rare congenital malformations (1-2/100 000 incidence) [1] located in the region of the tuber cinereum and third ventricle. This lesion is often associated with intractable seizures, cognitive impairment, behavioral disturbances and central precocious puberty. In fact, the manifestation of hypothalamic hamartoma is variant. Gelastic seizures as the hallmark are rare and are more likely to be diagnosed in early childhood. Patients later develop additional seizure types. The prevalence of epilepsy associated with hypothalamic hamartoma is estimated at 1 in 200,000 [2]. Recent functional MRI and intracranial electroencephalography (EEG) recordings have provided the proof that seizures originate in the hamartomas [3]. But some reports indicated another independent epileptogenesis [4], which is facilitated by the plethora of connections between the hypothalamus and the temporalfrontal lobe. On the other hand, gelastic seizures associated with $\mathrm{HH}$ are generally refractory to standard antiepileptic drugs as well as alternative therapies such as the ketogenic diet [5] and vagus nerve stimulation [6]. The detail of its mechanism and tailored treatment is still complicated issue. In the present review, we discuss the clinical characteristics and management of $\mathrm{HH}$ on the base of clinical experience and literature analysis.

\footnotetext{
* Correspondence: majie3004@163.com

Department of pediatric neurosurgery, Xinhua hospital, Shanghai JiaoTong University, Shanghai, China
}

(c) 2016 The Author(s). Open Access This article is distributed under the terms of the Creative Commons Attribution 4.0 International License (http://creativecommons.org/licenses/by/4.0/), which permits unrestricted use, distribution, and reproduction in any medium, provided you give appropriate credit to the original author(s) and the source, provide a link to the Creative Commons license, and indicate if changes were made. The Creative Commons Public Domain Dedication waiver (http://creativecommons.org/publicdomain/zero/1.0/) applies to the data made available in this article, unless otherwise stated.

\section{Clinical presentation}

Gelastic seizures GS

Gelastic seizures are usually present in childhood, even in the newborn period, and are manifested by frequent attacks of inappropriate laughter resulting from seizure activity. Gelastic epilepsy is characterized by recurrent brief seizures with initial laughter or grimacing. Without surgical intervention, most of gelastic seizures may progress to other seizure types such as tonic, myoclonic, or secondarily generalized seizures [7]. The association among hypothalamic hamartoma, central precocious puberty and gelastic seizures, has generated great interest since the time when Brening stall described the peculiar features of the syndrome $[8,9]$. The intimate relationship with the mammillary body, fornix and mammillothalamic tract plays an important role in epileptogenesis associated with HHs [10-12]. The evolution of electroencephalogram (EEG) abnormalities, the development of generalized seizures years after onset of GS and the postoperative running down of interictal spike-wave and generalized seizures in patients may reflect secondary epileptogenesis [13]. More studies have demonstrated the intrinsic epileptic character of the hamartoma [14, 15], as well as the excellent outcome of cases where surgical removal was possible [16-18]. These data indicate that GS originates in the $\mathrm{HH}$, and propagates to the 
hypothalamus and afterward to the neocortex. With the development of EEG and functional MRI, Someone reported that propagation of epileptic activity from the $\mathrm{HH}$ through the left fornix of the temporal lobe, and later through the cingulate fasciculus to the left frontal lobe [19]. The possibility of controlling seizures appears to In general, GS is pharmacoresistant and ends as a severe epileptic encephalopathy and catastrophic epilepsy of childhood [15, 20, 21]. The majority of patients with GS are male and present with a stalkless or sessile HH (Fig. 1), the majority of which distorted the third ventricle [22]. In the series of $\mathrm{HH}$ in Shanghai Xinhua hospital, $55 \%$ (22/40) children only presented with progressive refractory epilepsy, including GS, tonic-clonic seizure and other complicated partial seizure. And further $22.5 \%(9 / 40)$ demonstrated GS and CPP. Out of these $31 \mathrm{HHs}$ with GS, $74.2 \%(23 / 31)$ were male and $87.1 \%(27 / 31)$ lesions were mainly involved in the third ventricle. Furthermore. Its effects are determined by functional connections with critical brain regions: the mammillary bodies to cause seizures [23] and the tuber cinereum or infundibulum to cause central precocious puberty CPP [24]. The cellular mechanisms responsible for seizure activity are always mysterious. Altered gamma-amino-butyric acid (GABA) function may contribute to epileptogenesis in animal models. $\mathrm{Li}$ indicated that neurons from the sample of $\mathrm{HH}$ demonstrate functional rundown of GABAR-mediated transmembrane currents in response to GABA agonist exposure [25]. Further research indicated that GABAA receptor-mediated excitation may contribute to seizure genesis in $\mathrm{HH}$ tissue [26].

\section{Central precocious puberty CPP}

The majority (86.4 \%) of $\mathrm{HHs}$ in patients with isolated precocious puberty revealed a para-hypothalamic (Fig. 1b) position without touching the third ventricle [22, 27, 28]. Half of them were pedunculate and $40.9 \%$ of the masses showed a diameter less than $10 \mathrm{~mm}$ [22]. In our cases, the mean size of 40 lesions was measured at $18.6 \pm 7.7 \mathrm{~mm} ; 7$ cases with simple CPP showed the mean size of lesions $14.9 \pm 9.0 \mathrm{~mm}$ and $28.5 \%(2 / 7)$ of lesions demonstrated less than $10 \mathrm{~mm}$ diameter in MRI. Interestingly, mean size $21.7 \pm 5.2 \mathrm{~mm}$ of 9 lesions presenting with CPP and GS was larger than these cases with simple CPP. Immunohistochemistry studies revealed the presence of $\mathrm{GnRH}$-variant neurons in some HHs with CPP [29]. Hypothesis proposes that these neurons function as a heterotopic GnRH pulse-generator.
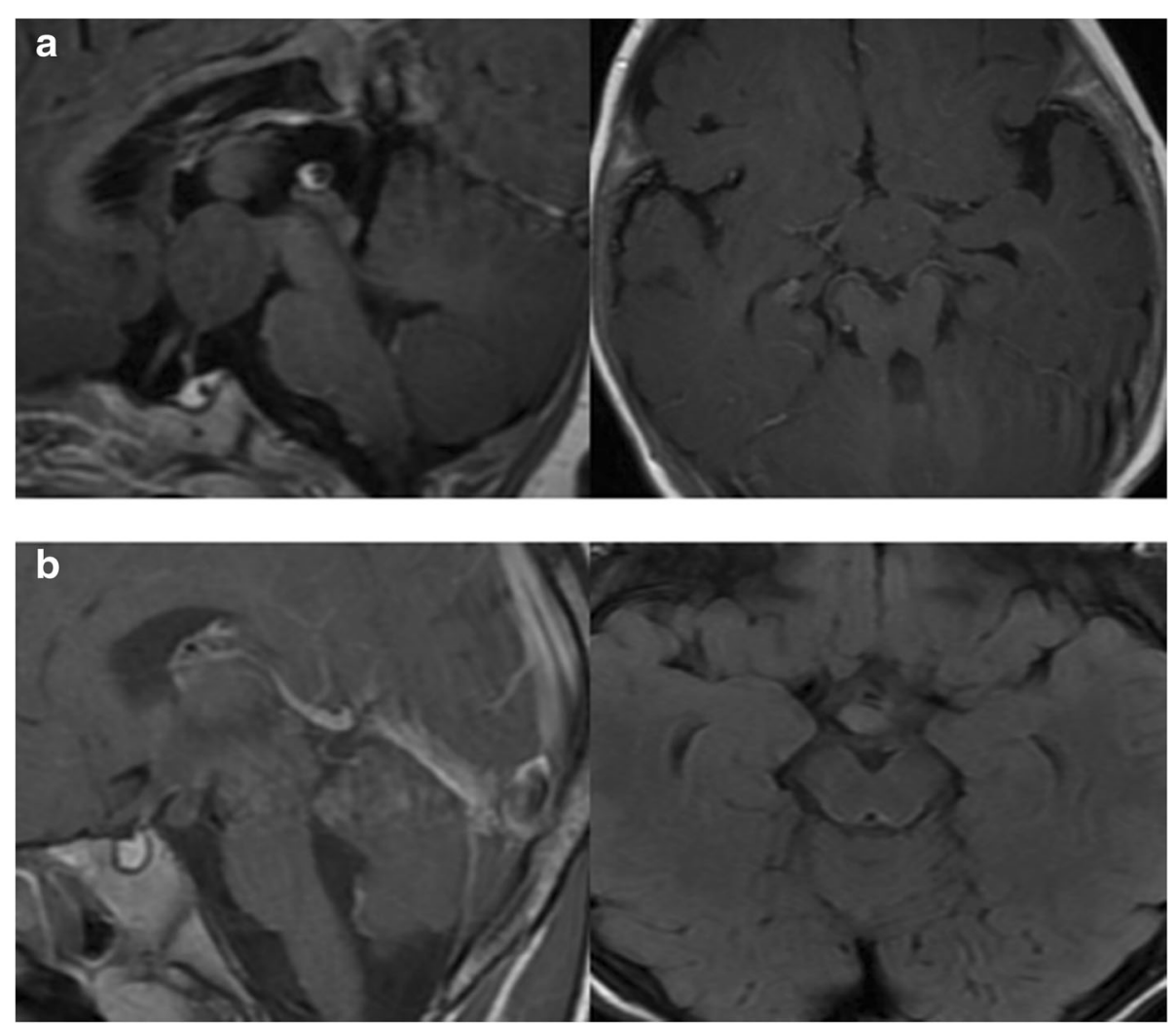

Fig. 1 a Sessile hypothalamic hamartoma, the mass allocates in the centre of Wills circle. b Pedunculated hypothalamic hamartoma, the patient with $\mathrm{HH}$ presented with single precocious puberty 
However, in other cases related to CPP, GnRH immunoreactivity was absent. Furthermore, most of $\mathrm{HHs}$ with $\mathrm{CPP}$ contacted the infundibulum or tuber cinereum and were larger than those not associated with precocious puberty [24]. The pathogenesis of these alterations of the CPP remains unknown. Heike reported that two $\mathrm{HHs}$ with CPP contained astroglial cells. Pathological examination showed that $\mathrm{HH}$ was usually composed of an intermixed array of neurons, glia, and myelinated fibers [30]. These research implies that some $\mathrm{HHs}$ induce sexual precocity by activating endogenous LHRH secretion via glia-derived factors.

\section{Cognitive malfunctions}

In a series of cases, children with $\mathrm{HH}$ involving cortical association areas and the amygdala and hippocampus formation displayed cognitive deficits to vary extent $[31,32]$. Almost half of the subjects had severe global memory deficits [33]. Both its severity and frequency in GS/complex partial seizure were related to cognizance. Ansgar suggested that more than half of the patients suffering from the GS of $\mathrm{HH}$ displayed deficits of cognitive functions such as visual and verbal learning and memory [33]. Another report described some patients of $\mathrm{HH}$ with cognitive deficit which includes $83.3 \%$ oppositional defiant disorder and $75 \%$ attention-deficit hyperactivity disorder [34]. The evaluation on cognitive abilities in patients with $\mathrm{HH}$ and GS report not only results on global intelligence quotient (IQ) performance but also other cognitive processes like attention or material-specific memory functions [35]. Furthermore, surgical resection is safe with a favorable outcome of epilepsy in $50 \%$ with significant improvement in behavior and marginal change in cognitive functions. The reasons for thinking that $\mathrm{HH}$ with GS play a major role on development [36] and behavior lie in the following considerations. These children with $\mathrm{HH}$ usually have no history of retarded or abnormal development before the onset of GS. HHs in themselves do not apparently interfere with development and behavior. Children with HHs, but without epilepsy do not present cognitive and behavioral problems $[9,37]$. Anatomical and functional imaging data in HH patients with GS do not identify dysplastic or brain malformations outside the hypothalamus [38]. Although the role of epilepsy severity is unclear, the number of antiepileptic drugs (AEDs) and neuroanatomical features of the $\mathrm{HH}$ lesion are recognized as being significantly related to patients' cognitive functions [32]. In fact, little is known about cognitive abilities in children with GS and $\mathrm{HH}$, especially in the development of the preschool period.

\section{Behavior disorder}

Significant rates of aggression/hyperactivity in $\mathrm{HH}$ were noted, with $58 \%$ of seizure patients meeting criteria for the affective subtype of aggression and $30.5 \%$ having the predatory aggressive subtype. Some reported that behavioral problems, especially aggressive behavior, are accompanied by epileptic syndrome [1, 39]. The final proof of a direct functional role of epilepsy in cognitive and behavioral changes can only be shown with certainty when there is a marked improvement in these fields with successful surgical therapy of epilepsy. Nishio has noted improved behavior and cognitive functions when seizures were controlled with surgery [16]. Recent study echoed it. Refractory epilepsy related to behavioral and cognitive dysfunction may be the most common presentation of HH. Open surgical resection is safe with a favorable outcome of epilepsy in $50 \%$ with significant improvement in behavior and marginal change in cognitive functions [36].

\section{Examination of laboratory \\ MRI}

A series of studies evaluated the use of brain MRI in the diagnosis of hypothalamic hamartomas [40]. In MRI, hypothalamic hamartomas were hyperintense on T2weighted images (93\%) and hypointense on T1-weighted images (74\%); none of the lesions was enhanced by contrast; malformations of cortical development were infrequent [23]. Hippocampus sclerosis was hardly observed [39]. HH can be described according to the nature of its attachment (broad-based, sessile or pedunculate), its maximal diameter $(<10 \mathrm{~mm}$ or $\geq 10$ $\mathrm{mm}$ ), growth characteristics (intra- or parahypothalamic) and the involvement of other brain structures (optic chiasm, infundibula stalk, the third ventricle). Para-hypothalamic growth was considered to be present if the $\mathrm{HH}$ was attached to the base of the hypothalamus either broad based or suspended by a peduncle, whereas an intra-hypothalamic hamartoma was defined as infiltrating the hypothalamic tissue. The pedunculate parahypothalamic type is generally associated with precocious puberty but is unaccompanied by seizures or developmental delay [22, 28]. According to our experiences, $\mathrm{HH}$ can be readily distinguished from normal hypothalamic gray and adjacent myelinated fiber tracts, best appreciated on thin T2-weighted images. Luo advised that $\mathrm{HH}$ consist of four categories based on MRI findings focused on the relationship between $\mathrm{HH}$ and hypothalamus or the third ventricle [41]. Furthermore, he suggested that the clinical manifestation is related to the topology of $\mathrm{HH}$ in relation to the hypothalamus. GS may be mostly presented in type III and rarely in type I. Recently, MRI is increasingly being employed as an adjunct to ultrasound, especially in a fetal brain. It allows for better visualization of in utero brain development and intracranial $\mathrm{HH}[42]$. 


\section{EEG}

The scalp EEG is usually normal in children with GS. Video EEG was performed in some cases with unspecific findings. Interictal EEG was abnormal in $87.5 \%$ patients with $\mathrm{HH}$. Almost all $\mathrm{HH}$ with seizure were refractory to ADEs [43]. A few children with $\mathrm{HH}$ suffering from an epileptic progression usually show lateral focal slowing and epileptiform activity on the interictal EEG [44]. With the appearance of generalized seizures, the interictal EEG shows bilaterally synchronous and generalized epileptiform activity. The mechanism of this evolution is incompletely understood. Neocortical seizure propagation and secondary epileptogenesis are deemed to be significant. Several studies of $\mathrm{HH}$ children with GS have reported a restricted participation of neocortical areas in epileptic activity $[45,46]$, with epileptic spikes involving predominantly the frontal or temporal areas, most often in a single hemisphere [3]. Intra-hamartoma spikes and slow waves were detected on depth electrode recordings. In our cases, intra-hamartoma and interictal EEG was benefit for the understand for seizure propagation and epileptogenesis (Fig. 2). Clinical signature for appropriate resection of hypothalamic hamartoma was the disappearance of epileptic spikes in the cortical EEG. However,there is insufficient evidence that video EEG monitoring ultimately affects the outcome of patients with $\mathrm{HH}[47]$.

\section{Pathology}

$\mathrm{HH}$ tissues consist of well-differentiated neurons interspersed with glial cells. In related literature, all cases are composed of normal neurons and glia. However, there are different in the cytology and distribution of cells. Neuronal elements predominate in most cases, but a relative increase in astrocytic elements may be regarded with increasing age. In pathology, various sized nodular foci of neurons and areas of diffusely distributed neurons with interspersed glial cells are prevalent. Smaller neurons predominate, and most cases had only a few interspersed large ganglion cells. In a word, mature smaller neurons were the most prominent and most consistent histologic character of $\mathrm{HH}$. Nodules of small neurons were an astonishing feature of the microarchitecture of $\mathrm{HH}$ lesions associated with epilepsy [30]. Qiu-pin found that various sized nodules of small neurons predominated with diffusely scattered small neurons and astrocytes between the nodules [48]. In other hands, Ben found that few solitary neurons can drive the development of GS and nodules of tiny neurons may not be a universal feature of $\mathrm{HHs}$ associated with epilepsy [49].

Approximately $5 \%$ of $\mathrm{HH}$ cases are linked to PallisterHall syndrome (PHS). David identified a somatic chromosomal abnormality on chromosome $7 \mathrm{p}$ in a $\mathrm{HH}$ tissue sample. Resequence of GLI3 did identify loss of heterozygosity (LOH) within the GLI3 gene in the $\mathrm{HH}$ tissue samples. David indicated that the development of chromosomal abnormalities within GLI3 is associated with the pathogenesis of $\mathrm{HH}$ lesions in sporadic, non-syndromic patients with $\mathrm{HH}$ and intractable epilepsy [50].

\section{Treatment}

Sometimes, patients with gelastic seizures can be misunderstood as a risible baby, and accurate diagnosis of $\mathrm{HH}$ takes many years. There is a distinct difference in outcome and complications between patients treated for GS and those treated for CPP alone. Delayed treatment can exacerbate the development of cognitive and behavior disturbances. Unfortunately, there is a different side to the treatment of $\mathrm{HH}$. When seizures are suspected, harm can also be done via invasive monitoring and inappropriate treatments, particularly surgery [51]. Recently, several surgical techniques can lead to a genuine reversal of the epileptic encephalopathy associated with $\mathrm{HH}$. The decision-making process depends on the age, the size, it's anatomical feature, and the severity of epilepsy and the severity of cognitive/behavior comorbidity [52]. All in all, there are about three main surgical techniques being widely accepted by clinical doers.

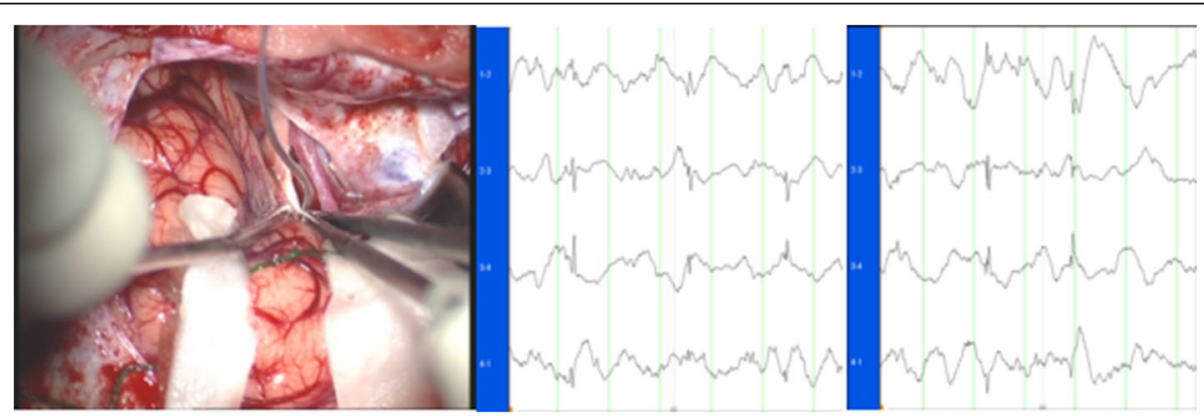

Fig. 2 In the process of lateral pterional approach for $\mathrm{HH}$, we clinched a series of intra-hamartoma spikes and slow waves by an intra-hamartoma EEG in operation. The results directly guided us the degree of resection 


\section{Microsurgery}

In appropriately selected patients, HHs can be removed completely or they can be completely disconnected from the hypothalamus as an acceptable risk [53]. It is possible to remove or disconnect the lesion from the adjacent hypothalamus in many patients without significant injury to the hypothalamus [54]. It is important to disconnect $\mathrm{HH}$ lesion from the mammillary body and the rest of the hypothalamus to achieve control of the seizures. In China, [55] Luo documented a series of six children with hypothalamic hamartoma-induced CPP who underwent microsurgical treatment. Significant prognostic factors for surgical outcome were $\mathrm{HH}$ size, surgical approach, and resection level. Patients with $\mathrm{HH}$ totally within the third ventricle have the best outcome from surgery [56]. All of them recovered completely to their age-appropriate state. Microsurgery is a great choice of treatment for pedunculate $\mathrm{HH}$.

Surgical resection/disconnection of $\mathrm{HH}$ typically is taken into account when the associated seizures are refractory. No study was found that compared the seizure outcome between resection and disconnection. About operative techniques, the transcallosal anterior interforniceal approach to $\mathrm{HH}$ resection has been shown to be safe and to result in good seizure frequency reduction [57]. The transcallosal anterior transseptal interforniceal technique is an effective and relatively safe technique when used for the resection of $\mathrm{HH}$ [58]. This operative approach is applicable to other pathology in the hypothalamic region and has advantages compared with the standard transcallosal approach to the third ventricle [59]. Recently, Jacqueline documented that approach to $\mathrm{HH}$ resection is associated with a high risk of long-term memory impairment in older adolescents [57]. Charles compared three surgical approaches [52]: one lateral pterional, another midline frontal through the lamina terminals and a third transcallosal interforniceal approach. A disconnection procedure, usually lateral pterional, aims to disconnect the lesion without the risks of major resection. The transcallosal interforniceal approach is the most successful with $69 \%$ of patients seizure-free. Iman reviewed [60] his reports and related literatures. Their lesions were approached from above through a transcallosal anterior interforniceal approach in six, endoscopically through the foramen of Monro in one, and from below with a frontotemporal craniotomy including an orbitozygomatic osteotomy in three. Sessile lesions are best approached from above. Approaches from below adequately expose pedunculate HHs. The likelihood of curing seizures appears to be higher when lesions are approached from above rather than from below. Of course, those patients with both intrahypothalamic and parahypothalamic components may require approaches from above and below. For appropriately selected patients, the success of controlling seizures with an orbitozygomatic (OZ) pterional surgery is comparable to results utilizing transcallosal or transventricular approaches [61]. Currently, the traditional effective surgical route appears to be the transcallosal anterior interforniceal approach [62]. There is a question for complicating $\mathrm{HH}$ : The different partial resection of lesions based on separate approach of microsurgery showed a similar outcome of controlling seizures in literature. In the center of the author, most of the patients were received lateral pterional microsurgery. And half of these patients still suffered from diverse epilepsy, comprehensive effect of which was less to the one reported in previous $\mathrm{HH}$ literature. However, Four patients underwent endoscopic resection of transcallosal anterior transseptal interforniceal technique. Out of these patients, three patients were protected from severe seizures. Surgical complications included thalamic infarct, visual deficits, diabetes insipidus short-term memory impairment, and hydrocephalus.

\section{Endoscopy}

Although $\mathrm{HH}$ can be controlled by microsurgical resection of the lesion, excision of deep-seated lesions is often associated with morbidity and mortality. Endoscopic disconnection is less invasive and seems to be well suited for a similar indication. Endoscopic disconnection appears to be a very safe way to treat hamartomas in intraventricular locations [63]. Joong-Uhn advocated the endoscopic disconnection surgery as a safe and effective treatment for $\mathrm{HH}$-related epilepsy by blocking the spread of epileptic discharges from the lesion [64]. There is increasing evidence that removal or disconnection of $\mathrm{HH}$ can lead to seizure control and improvement in behavior. Shim suggests [65] that HH-related seizures may be controlled by blocking the seizure propagation from epileptogenic $\mathrm{HHs}$ through simple disconnection, regardless of the treatment modality. Ng YT evaluated the efficacy of endoscopic resection of HHs and compared the seizure outcome with a prior reported transcallosal approach. Forty-nine percent were seizure-free, and $71 \%$ had a more than $90 \%$ decreases in seizure frequency. After comparison endoscopic resection with the transcallosal approach, the authors did not find any significant difference in seizure outcome [66]. Recently, new case reports showed that endoscopic disconnection of $\mathrm{HH}$ resulted in rapid resolution of neurological symptomatology [67]. In fact, some cases of author echoed the advance: minimally invasive endoscopic surgery for HHs may represent an effective alternative to the open procedures.

\section{Radiosurgery: GKS and SRT}

Jean Régis indicated that gamma knife surgery (GKS) is as effective as microsurgical resection and safer [68]. 
GKS also allows avoiding the vascular risk related to radiofrequency lesion or stimulation. Adib [69] showed that GKS was associated with few complications and about $60 \%$ seizure-free rate as part of a multimodal treatment protocol. Another $30 \%$ of patients experienced an astonishing improvement (Engel Class III) after GKS. In 2000, Régis reported a series of 8 patients, with $50 \%$ cases attaining Engel Class I by GKS. The data were updated in 2006 to include more than 60 patients who had undergone GKS [68]. Some doctors suggested that resection of epilepsy-related HHs may be replaced by disconnection procedures. Their results confirm disconnection procedure feasible and acceptable morbidity, and particularly good seizure outcome in patients with intraventricularly located HHs [70]. A stereotactic surgical plan was devised to disconnect the $\mathrm{HH}$ from the hypothalamus, medial forebrain bundle and dorsal longitudinal fasciculus [71]. Seizure frequency was reduced from several seizures per day to less than one tonicclonic seizure during sleep per month. The disadvantage of radiosurgery is its delayed action [68]. The immediate effect on sub-clinical discharges turns out to play a major role in the dramatic improvement of sleep quality, behavior, and developmental learning acceleration at school. Recently, some centers introduced that stereotactic laser ablation (SLA) is a minimally invasive approach to the treatment of medication-resistant epilepsy. SLA minimizes the neurocognitive and endocrine adverse effects of open surgery [72]. The evaluation and safety of radiosurgery in children are still at multifaceted observation.

In China, some documents suggested that stereotactic radiofrequency thermocoagulation (SRT) may be an effective and safe treatment option in selected cases of HHGS [73]. Transient central hyperthermia, hypertension, and tachycardia were observed during the coagulation procedure. No gelastic seizure was induced by deep stimulation. Central hyperthermia and postoperative fever after stereotactic thermocoagulation occurred more frequently compared to using the open approach, the disadvantages of stereotactic radiofrequency thermocoagulation are acceptable. Kameyama suggested [74] that the present SRT procedure has favorable efficacy and invasiveness and has no adaptive limitations. Recent reports are [75] showed that SRT provided minimal invasiveness and excellent seizure outcomes even in patients with giant HHs. Repeat SRT is prudent for residual GS. SRT is a single feasible surgical strategy for $\mathrm{HH}$ regardless of the tumor's size or shape.SRT should therefore be considered before adulthood.

\section{Conclusion}

Hypothalamic hamartoma is a nonneoplastic heterotopic mass of normal nervous tissue. Its usual manifestations include gelastic seizure, central precocious puberty and cognitive malfunctions due to AEDs and epileptic encephalopathy. The clinical presentations of $\mathrm{HHs}$ and option of treatment may base on its anatomy. Magnetic Resonance Imaging investigation is mandatory in its diagnosis although EEG is lack of its specificity. Neurosurgery plays the most important role in its treatment and endoscopic disconnection of $\mathrm{HHs}$ is a promising choice with safety and validity.

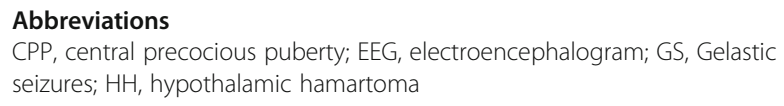

Funding

This work was supported by grants from the National Key Basic Research Program, (NKBRP 2010CB945203), the National Natural Science Foundation of China (81271382); Clinical Trials of Xinhua hospital (Shanghai Jiao Tong University 2015LC12).

Availability of data and materials

Not applicable.

\section{Authors' contributions}

BW drafted the manuscript. JM conceived of the study, and helped to draft the manuscript. All authors read and approved the final manuscript.

Competing interests

The authors declare that they have no competing interests.

Consent for publication

Not applicable.

Ethics approval and consent to participate

Not applicable.

Received: 22 March 2016 Accepted: 27 July 2016

Published online: 18 September 2016

References

1. Weissenberger AA, Dell ML, Liow K, Theodore W, Frattali CM, Hernandez D, et al. Aggression and psychiatric comorbidity in children with hypothalamic hamartomas and their unaffected siblings. J Am Acad Child Adolesc Psychiatry. 2001;40:696-703.

2. Shahar E, Kramer U. MahajnahM, et al. Pediatric-onset gelastic seizures: clinical data and outcome. Pediatr Neurol. 2007;37:29-34

3. Leal AJR, Monteiro JP, Secca MF, et al. Functional brain mapping of ictal activity in gelastic epilepsy associated with hypothalamic hamartoma: a case report. Epilepsia. 2009;50:1624-31.

4. Wu J, Gao M, Shen JX, Qiu SF, Kerrigan JF. Mechanisms of intrinsic epileptogenesis in human gelastic seizures with hypothalamic hamartoma. CNS Neurosci Ther. 2015;21(2):104-11.

5. Chapman KE, Kim DY, Rho JM, Ng YT, Kerrigan JF. Ketogenic diet in the treatment of seizures associated with hypothalamic hamartomas. Epilepsy Res. 2011;94(3):218-21.

6. Kawai K. Less invasive treatment of intractable epilepsy- vagus nerve stimulation and stereotactic radiosurgery. Brain Nerve. 2007;59(4):299-311.

7. Valentin A, Lazaro M, Mullatti N, Cervantes S, Malik I, Selway RP, et al. Cingulate epileptogenesis in hypothalamic hamartoma. Epilepsia. 2011;52(5):e35-9.

8. Breningstall GN. Gelastic seizures, precocious puberty, and hypothalamic hamartoma. Neurology. 1985;35(8):1180-3.

9. Arroyo S, Lesser RP, Gordon B, Uematsu S, Hart J, Schwerdt P, Andreasson K, Fisher RS. Mirth, laughter and gelastic seizures. Brain. 1993;116(Pt 4):757-8. 
10. Miller MJ, Mark LP, Yetkin FZ, et al. Imaging white matter tracts and nuclei of the hypothalamus: an MRanatomic comparative study. AJNR Am J Neuroradiol. 1994;15:117-21.

11. Saeki N, Sunami K, Kubota M, et al. Heavily T2-weighted MR imaging of white matter tracts in the hypothalamus: normal and pathologic demonstrations. AJNR Am J Neuroradiol. 2001;22:1468-75.

12. Jeremy L. Freeman, Lee T. Coleman, R. Mark Wellard, Michael J. Kean, Jeffrey V. Rosenfeld, Graeme D. Jackson, Samuel F. Berkovic, and A. Simon Harvey. MR Imaging and Spectroscopic Study of Epileptogenic Hypothalamic Hamartomas: Analysis of 72 Cases. AJNR Am J Neuroradiol 2004;25:450-62.

13. Freeman JL, Harvey AS, Rosenfeld JV, Wrennall JA, Bailey CA, Berkovic SF. Generalized epilepsy in hypothalamic hamartoma: evolution and postoperative resolution. Neurology. 2003;60:762-7.

14. Munari C, Kahane P, Francione S, Hoffmann D, Tassi L, Cusmai R, Vigevano F, Pasquier B, Betti OO. Role of the hypothalamic hamartoma in the genesis of gelastic fits (a video-stereo-EEG study). Electroencephalogr Clin Neurophysiol. 1995;95(3):154-60.

15. Kuzniecky R, Guthrie B, Montz J. Intrinsic epileptogenesis of hypothalamic hamartoma in gelastic epilepsy. Ann Neurol. 1997;42:60-7.

16. Nishio S, Morioka T, Fukui M, Goto Y. Surgical Treatment of Intractable Seizures Due to Hypothalamic Hamartoma. Epilepsia. 1994;35(3):514-9.

17. Fohlen $\mathrm{M}$, Lellouch $\mathrm{A}$, Delalande $\mathrm{O}$. Hypothalamic hamartoma with refractory epilepsy: surgical procedures and results in 18 patients. Epileptic Disord. 2003;5(4):267-73

18. Rosenfeld JV, Feiz-Erfan I. Hypothalamic hamartoma treatment: surgical resection with the transcallosal approach. Semin Pediatr Neurol. 2007;14(2):88-98.

19. Alberto JR. Leal, José P. Monteiro, Mário Forjaz Secca, et al. Functional brain mapping of ictal activity in gelastic epilepsy associated with hypothalamic hamartoma: A case report. Epilepsia. 2009:50(6):1624-31.

20. Curatolo P, Cusmai R. Gelastic seizures, precocious puberty, and hypothalamic hamartoma. Neurology. 1986;36(3):443-4.

21. Palmini A, Chandler C, Andermann F, Costa Da Costa J, Paglioli-Neto E, Polkey C, Rosenblatt B, Montes J, Martínez JV, Farmer JP, Sinclair B, Aronyk K, Paglioli E, Coutinho L, Raupp S, Portuguez M. Resection of the lesion in patients with hypothalamic hamartomas and catastrophic epilepsy. Neurology. 2002;58(9):1338-47.

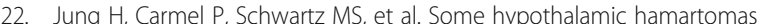
contain transforming growth factor alpha, a puberty-inducing growth factor, but not luteinizing hormone-releasing hormone neurons. J Clin Endocrinol Metab. 1999;84:4695-701.

23. Freeman JL, Coleman LT, Wellard RM, Kean MJ, Rosenfeld JV, Jackson GD, Berkovic SF, Harvey AS. MR Imaging and Spectroscopic Study of Epileptogenic Hypothalamic Hamartomas: Analysis of 72 Cases. AJNR Am J Neuroradiol. 2004;25:450-62.

24. Yee-Ming C, Fenoglio-Simeone KA, et al. Central Precocious Puberty due to Hypothalamic Hamartomas Correlates with Anatomic Features but Not with Expression of GnRH, TGFa, or KISS1. Seminara Hormone Res Pediatrics. 2010;73(5):312-9.

25. Li G, Yang K, Zheng $C$, et al. Functional rundown of gamma-aminobutyric acidA receptors in human hypothalamic hamartomas. Ann Neurol. 2011;69(4):664-72.

26. Do Young K, Fenoglio KA, Simeone TA, et al. GABAA receptor-mediated activation of L-type calcium channels induces neuronal excitation in surgically resected human hypothalamic hamartomas. Epilepsia. 2008;49(5):861-71.

27. Veldueza J, Cristante L, Dammann O, et al. Hypothalamic hamartomas: with special reference to gelastic epilepsy and surgery. Neurosurgery. 1994;34:949-58.

28. Arita K, Ikawa F, Kurisu K, Sumida M, Harada K, Uozumi T, Monden S, Yoshida J, Nishi Y. The relationship between magnetic resonance imaging findings and clinical manifestations of hypothalamic hamartoma. J Neurosurg. 1999;91(2):212-20.

29. Amin MS, Kader MA, Huq FI, Khan NA. Hypothalamic hamartoma with precocious puberty: a case report. Mymensingh Med J. 2012;21(3):553-6.

30. Coons SW, Rekate HL, Prenger EC, Wang N, Drees C, Ng YT, et al. The histopathology of hypothalamic hamartomas: study of 57 cases. J Neuropathol Exp Neurol. 2007;66(2):131-41.

31. Ali S, Moriarty J, Mullatti N, David A. Psychiatric comorbidity in adult patients with hypothalamic hamartoma. Epilepsy Behav. 2006;9:111-8.

32. Prigatano GP, Wethe JV, Gray JA, et al. Intellectual functioning in presurgical patients with hypothalamic hamartoma and refractory epilepsy. Epilepsy Behav. 2008;13:149-55
33. Quiske A, Frings L, Wagner K, Unterrainer J, Schulze-Bonhage A. Cognitive functions in juvenile and adult patients with gelastic epilepsy due to hypothalamic hamartoma. Epilepsia. 2006;47:153-8.

34. Weissenberger AA, Del ML, Liow K, Theodore W, Frattali CM, Hernandez D, Zametkin AJ. Aggression and psychiatric comorbidity in children with hypothalamic hamartomas and their unaffected siblings. J Am Acad Child Adolesc Psychiatry. 2001;40(6):696-703.

35. Nguyen D, Singh S, Zaatreh M, Novotny E, Levy S, Testa F, Spencer SS Hypothalamic hamartomas: seven cases and review of the literature. Epilepsy Behav. 2003;4(3):246-58.

36. Jayalakshmi S, Panigrahi M, Reddy R, Somayajula S. Clinical characteristics and long-term outcome of surgery for hypothalamic hamartoma in children with refractory epilepsy. Ann Indian Acad Neurol. 2014;17(1):43-7.

37. Stewart L, Steinbok P, Daaboul J. Role of surgical resection in the treatment of hypothalamic hamartomas causing precocious puberty. Report of six cases. J Neurosurg. 1998;88(2):340-5.

38. Berkovic SF, Andermann F, Melanson D, Ethier RE, Feindel W, Gloor P. Hypothalamic hamartomas and ictal laughter: evolution of a characteristic epileptic syndrome and diagnostic value of magnetic resonance imaging. Ann Neurol. 1988;23(5):429-39.

39. Schulze-Bonhage A, Trippel M, Wagner $\mathrm{K}$, et al. Outcome and predictors of interstitial radiosurgery in the treatment of gelastic epilepsy. Neurology. 2008;71:277-82

40. Amstutz DR, Coons SW, Kerrigan JF, Rekate HL, Heiserman JE. Hypothalamic hamartomas: correlation of MR imaging and spectroscopic findings with tumor glial content. Am J Neuroradiol. 2006;27:794-8.

41. Luo S-q, Chun-de L, Ma Z-y, et al. Classification of hypothalamic hamartoma according to the clinical manifestations of 214 cases Chinese. J Neurosurgery. 2009;25(9):788-92.

42. Celedin S, Kau T, Gasser J, et al. Fetal MRI of a Hypothalamic Hamartoma in Pallister-Hall Syndrome. Pediatr Neurol. 2010;42(1):59-60.

43. Papayannis CE, Consalvo D, Seifer $G$, et al. Clinical spectrum and difficulties in management of hypothalamic hamartoma in a developing country. Acta Neurol Scand. 2008;118(5):313-9.

44. Simon Harvey A, Freeman JL. Epilepsy in Hypothalamic Hamartoma: Clinical and EEG Features. Semin Pediatr Neurol. 2007;14(2):60-4.

45. Mullatti N, Selway R, Nashef L, Elwes R, Honavar M, Chandler C, Morris R, Jarosz J, Buchanan C, Polkey C. The clinical spectrum of epilepsy in children and adults with hypothalamic hamartoma. Epilepsia. 2003:44(10):1310-9.

46. Ryvlin P, Ravier C, Bouvard S, Mauguire F, Le Bars D, Arzimanoglou A, Petit J, Kahane P. Positron emission tomography in epileptogenic hypothalamic hamartomas. Epileptic Disord. 2003:5(4):219-27.

47. Troester $M$, Haine-Schlagel $R, N g$ YT, et al. EEG and video-EEG monitoring has limited utility in patients with hypothalamic hamartoma and epilepsy. Epilepsia. 2011;52:1137-43.

48. Gui Q-p, Yuan Z, Song X. Hypothalamic hamartoma: a clinicopathological analysis of 9 cases. Chinese J Diagnostic Pathol. 2011;18(2):106-9.

49. Ben W, McLendonb RE, Fuchsa HE, et al. Few Isolated Neurons in Hypothalamic Hamartomas May Cause Gelastic Seizures. Pediatr Neurosurg. 2009;45:225-9.

50. Locus DW. Craig, Abraham Itty, Corrie Panganiban, et al. Identification of Somatic Chromosomal Abnormalities in Hypothalamic Hamartoma Tissue at the GLI3. Am J Hum Genet. 2008:82(2):366-74.

51. Cascino GD, Andermann F, Berkovic SF, Kuzniecky Rl, Sharbrough FW, Keene DL, Bladin PF, Kelly PJ, Olivier A, Feindel W. Gelastic seizures and hypothalamic hamartomas: evaluation of patients undergoing chronic intracranial EEG monitoring and outcome of surgical treatment. Neurology. 1993:43(4):747-50

52. Polkey CE. Resective surgery for hypothalamic hamartoma. Epileptic Disord. 2003:5(4):281-6

53. Rekate HL, Feiz-Erfan I, Ng Y-T, et al. Endoscopic surgery for hypothalamic hamartomas causing medically refractory gelastic epilepsy. Childs Nerv Syst. 2006;22(8):874-80.

54. Rosenfeld JV, Simon Harvey A. Hypothalamic Hamartoma. Oncol CNS Tumors. 2010;Part Il:491-502.

55. Luo S, Li C, Ma Z, Zhang Y, Jia G, Cheng Y. Microsurgical treatment for hypothalamic hamartoma in children with precocious puberty. Surg Neurol. 2002:57(5):356-62

56. Li CD, Luo SQ, Tang J, Jia G, Ma ZY, Zhang YQ. Classification of hypothalamic hamartoma and prognostic factors for surgical outcome. Acta Neurol Scand. 2014;130(1):18-26. 
57. Jacqueline FI. Anderson, Jeffrey V. Rosenfeld. Long term cognitive outcome after transcallosal resection of hypothalamic hamartoma in older adolescents and adults with gelastic seizures. Epilepsy Behav. 2010;18(1-2):81-7.

58. Ng YT, Rekate HL, Prenger EC, et al. Transcallosal resection of hypothalamic hamartoma for intractable epilepsy. Epilepsia. 2006;47:1192-202.

59. Rosenfeld JV, Freeman JL, Harvey AS. Operative technique: the anterior transcallosal transseptal interforniceal approach to the third ventricle and resection of hypothalamic hamartomas. J Clin Neurosci. 2004;11(7):738-44.

60. Feiz-Erfan I, Horn EM, Rekate HL, Spetzler RF, Ng YT, Rosenfeld JV, Kerrigan JF. Surgical strategies for approaching hypothalamic hamartomas causing gelastic seizures in the pediatric population: transventricular compared with skull base approaches. J Neurosurg. 2005; 103(4 Suppl):325-32.

61. Abla AA, Rekate HL, Wilson DA, et al. Orbitozygomatic resection for hypothalamic hamartoma and epilepsy: patient selection and outcome. Childs Nervous System. 2011;27, I(2):265-77.

62. Maixner W. Hypothalamic hamartomas-clinical, neuropathological and surgical aspects. Childs Nerv Syst. 2006;22(8):867-73.

63. Delalande O, Fohlen M.Disconnecting surgical treatment of hypothalamic hamartoma in children and adults with refractory epilepsy and proposal of a new classification.Neurol Med Chir (Tokyo). 2003:43(2):61-8.

64. Choi JU, Yang KH, Kim TG, Chang JH, Chang JW, Lee Bl, Kim DS.Endoscopic disconnection for hypothalamic hamartoma with intractable seizure. Report of four cases. J Neurosurg. 2004; 100(5 Suppl Pediatrics):506-11.

65. Kyu-Won S, Jong-Hee C, Yong-Gou P, et al. Treatment Modality for Intractable Epilepsy in Hypothalamic Hamartomatous Lesions. Neurosurgery. 2008;62(4):847-56

66. $\mathrm{Ng}$ YT, Rekate HL, Prenger EC, et al. Endoscopic resection of hypothalamic hamartomas for refractory symptomatic epilepsy. Neurology. 2008;70:1543-8.

67. Incorpora G, Pavone P, Castellano-Chiodo D, Pratico AD, Ruggieri M, Pavone L. Gelastic seizures due to hypothalamic hamartoma: rapid resolution after endoscopic tumor disconnection. Neurocase. 2013;19(5):458-61.

68. Régis J, Scavarda D, Tamura M, et al. Epilepsy related to hypothalamic hamartomas: surgical management with special reference to gamma knife surgery. Childs Nerv Syst. 2006;22:881-95.

69. Abla AA, Shetter AG, Chang SW, et al. Gamma Knife surgery for hypothalamic hamartomas and epilepsy: patient selection and outcomes. J Neurosurg. 2010;113(S):207-14.

70. Dorfmüller G, Fohlen M, Bulteau C, et al. Surgical disconnection of hypothalamic hamartomas. Neurochirurgie. 2008;54(3):315-9.

71. de Almeida AN, Erich Talamoni F, Gerson B, et al. Stereotactic disconnection of hypothalamic hamartoma to control seizure and behavior disturbance: case report and literature review. Neurosurg Rev. 2008;31(3):343-9.

72. Rolston JD, Chang EF. Stereotactic Laser Ablation for Hypothalamic Hamartoma. Neurosurg Clin N Am. 2016;27(1):59-67.

73. Wang W, Wang W, Guo X, et al. Hypothalamic hamartoma causing gelastic seizures treated with stereotactic radiofrequency thermocoagulation. Epileptic Disord. 2009:11(4):333-8.

74. Shigeki K, Hiroatsu M, Hiroshi M, et al. Minimally Invasive Magnetic Resonance Imaging-Guided Stereotactic Radiofrequency Thermocoagulation for Epileptogenic Hypothalamic Hamartomas. Neurosurgery. 2009;65(3):438-49.

75. Shirozu H, Masuda H, Ito Y, Sonoda M, Kameyama S. Stereotactic radiofrequency thermocoagulation for giant hypothalamic hamartoma. J Neurosurg. 2016;VN:1-10

\section{Submit your next manuscript to BioMed Central and we will help you at every step:}

- We accept pre-submission inquiries

- Our selector tool helps you to find the most relevant journal

- We provide round the clock customer support

- Convenient online submission

- Thorough peer review

- Inclusion in PubMed and all major indexing services

- Maximum visibility for your research

Submit your manuscript at www.biomedcentral.com/submit
Biomed Central 